\title{
Increased Readmission Risk and Healthcare Cost for Delirium Patients without Immediate Hospitalization in the Emergency Department
}

\author{
I Chun Ma', Kao Chin Chen ${ }^{2}$, Wei Tseng Chen ${ }^{2}$, Hsin Chun Tsai ${ }^{2,3}$, Chien-Chou Su' ${ }^{2}$ Ru-Band Lu ${ }^{2,4}$, \\ Po See Chen ${ }^{2,4}$, Wei Hung Chang ${ }^{2,5, *}$, Yen Kuang Yang ${ }^{2,3,4}$ \\ Departments of ${ }^{1}$ Emergency Medicine and ${ }^{2}$ Psychiatry, National Cheng Kung University Hospital, College of Medicine, National Cheng Kung \\ University, Tainan, ${ }^{3}$ Department of Psychiatry, National Cheng Kung University Hospital, Dou-Liou Branch, Yunlin, ${ }^{4}$ Institute of Behavioral \\ Medicine and ${ }^{5}$ Institute of Clinical Medicine, College of Medicine, National Cheng Kung University, Tainan, Taiwan
}

\begin{abstract}
Objective: Hospitalization of patients with delirium after visiting the emergency department (ED) is often required. However, the readmission risk after discharge from the ED should also be considered. This study aimed to explore whether (i) immediate hospitalization influences the readmission risk of patients with delirium; (ii) the readmission risk is affected by various risk factors; and (iii) the healthcare cost differs between groups within 28 days of the first ED visit.

Methods: Using the National Health Insurance Research Database, the data of 2,780 subjects presenting with delirium at an ED visit from 2000 to 2008 were examined. The readmission risks of the groups of patients (i.e., patients who were and were not admitted within 24 hours of an ED visit) within 28 days were compared, and the effects of the severities of different comorbidities (using Charlson's comorbidity index, CCl), age, gender, diagnosis and differences in medical healthcare cost were analyzed.

Results: Patients without immediate hospitalization had a higher risk of readmission within 3, 7, 14, or 28 days of discharge from the ED, especially subjects with more severe comorbidities $(\mathrm{CCl} \geq 3)$ or older patients ( $\geq 65$ years). Subjects with more severe comorbidities or older subjects who were not admitted immediately also incurred a greater healthcare cost for re-hospitalization within the 28-day follow-up period.

Conclusion: Patients with delirium with a higher $\mathrm{CCl}$ or of a greater age should be carefully considered for immediate hospitalization from ED for further examination in order to reduce the risk of re-hospitalization and cost of healthcare.
\end{abstract}

KEY WORDS: Delirium; Hospital emergency service; Health care costs; Re-hospitalization; Risk factors.

\section{INTRODUCTION}

Current evidence indicates that delirium is multi-factorial, and certain illnesses carry a higher risk of delirium. ${ }^{1)}$ Therefore, inappropriate management of delirium may result in a poor prognosis, especially in elderly patients. ${ }^{2)}$

Recognition of delirium is challenging in the emergency department (ED), because clinicians may be unfamiliar with the symptoms presented, ${ }^{3)}$ or may have a

Received: November 29, 2017 / Revised: January 26, 2018 Accepted: March 5, 2018

Address for correspondence: Wei Hung Chang, MD Department of Psychiatry, National Cheng Kung University Hospital, 138 Sheng Li Road, North Dist., Tainan 70403, Taiwan Tel: +886-6-2353535 ext. 5189, Fax: +886-6-2084767

E-mail: weihung2364009@gmail.com

ORCID: https://orcid.org/0000-0002-5964-106X heavy workload. ${ }^{4)}$ Moreover, even if the diagnosis of delirium is confirmed, clinicians may discharge potentially unstable patients or those in high-risk groups (such as older patients) ${ }^{2,5,6)}$ due to a temporary improvement in their symptoms $^{3}$; this might lead to re-hospitalization soon after discharge owing to their original medical problems. ${ }^{7)}$ Therefore, suitable decisions with regards to immediate hospitalization in the ED with appropriate management would effectively reduce the length of hospitalization for patients with delirium, ${ }^{8)}$ and potentially the risk of readmission.

More importantly, the severities of physical illnesses also affect the risk of hospitalization in patients with delirium. ${ }^{9)}$ Therefore, a useful and reliable index scaled to account for the severities of physical comorbidities may

(c) This is an Open-Access article distributed under the terms of the Creative Commons Attribution Non-Commercial License (http://creativecommons.org/licenses/by-nc/4.0) which permits unrestricted non-commercial use, distribution, and reproduction in any medium, provided the original work is properly cited. 
present a better method by which to evaluate the risks associated with delirium. Charlson's comorbidity index (CCl), developed by Charlson et al.,, ${ }^{10)}$ was designed to evaluate the prognosis when patients are suffering from different levels of severity of physical comorbidities, and has a good reliability. ${ }^{11)}$ By using medical records rather than direct clinical observation, the total score obtained by the $\mathrm{CCl}$ reflects the severities of comorbidities and other clinical outcomes. ${ }^{11-13)}$ Previous studies have used this index to estimate the length of hospitalization ${ }^{12,13)}$ and the risk of requiring a repeat visit to the ED for patients with delirium. ${ }^{14)}$ However, the correlation between comorbidity severities as measured by the $\mathrm{CCl}$ and readmission risk in patients with delirium is not currently well understood.

In addition to the re-hospitalization risk, the burden of healthcare cost in patients with delirium is also of concern. ${ }^{15)}$ Repeat hospital visits unquestionably increase the cost burden. To conclude, it is important that ED clinicians take the correct decision as to whether patients with delirium should be hospitalized or not in order to reduce the risk of readmission, as well as the healthcare cost.

Therefore, through analysis of healthcare system data from 2000 to 2008, we aimed to explore whether (i) immediate hospitalization influences the readmission risk in patients with delirium; (ii) the readmission risk is affected by different risk factors, focusing on the severities of physical illnesses by $\mathrm{CCl}$ evaluation and age with reference to existing evidence; and (iii) healthcare costs differ between the patient groups within 28 days of the first ED visit.

\section{METHODS}

\section{Patient Sample and Disease Inclusion}

The research protocol was approved by the Ethical Committee for Human Research at the National Cheng Kung University (No. B-ER-104-299). The National Health Insurance (NHI) program in Taiwan is a universal health program, in which greater than $99 \%$ of the population of Taiwan is enrolled. ${ }^{16)}$ The National Health Research Institute established and manages the National Health Insurance Research Database (NHIRD). In this study, we used a sub-dataset of the NHIRD, which contains longitudinal claims data for a randomly-selected cohort of one million people from all insured beneficiaries in 2000. We used three different data files: registry of beneficiaries, inpatient claims, and ambulatory care claims. All NHI data- sets can be interlinked using each individual personal identification number.

We conducted a retrospective, population-based, observational cohort study among patients who were newly-diagnosed with delirium at an emergency room (ER) visit between 2000 and 2008. The diagnosis of delirium was confirmed from the recorded ICD code (International Classification of Diseases, Ninth Revision, Clinical Modification, ICD-9-CM codes: 290.11 presenile dementia with delirium; 290.3 senile dementia with delirium; 290.41 arteriosclerotic dementia with delirium; 291.0 alcohol withdrawal delirium; 292.81 drug-induced delirium; 293.0 acute delirium; 293.1 subacute delirium; 780.09 other alteration of consciousness).

We categorized the patients into two groups in this study. The first group consisted of those patients presenting with delirium at an ER visit who were hospitalized within 24 hours. The second group included patients with delirium at an ER visit who were not hospitalized within 24 hours, or were not hospitalized at all. The index date was defined as the date of patient discharge from hospital, and both groups were followed-up to evaluate the risk of readmission within 3, 7, 14 and 28 days after the index date. Readmission was defined as patients who were hospitalized or who made an ER visit for any reason after the index date. The reason for the selection of 24 hours as the cut-off point was related to patient prognosis in the ED. ${ }^{17)}$ In addition, evidence has demonstrated that a stay of greater than 24 hours in the ED increases the risk of lengthening the hospitalization duration and results in a greater mortality rate. ${ }^{17)}$ Regarding medical healthcare cost, the medical cost of readmission was analyzed within 28 days after the index date.

\section{Charlson's Comorbidity Index (CCl)}

The $\mathrm{CCl}$ was developed by Charlson et al., ${ }^{10)}$ and is widely used to summarize patient comorbidities. Deyo et al. ${ }^{18)}$ adapted the $\mathrm{CCl}$ for use with ICD-9-CM diagnostic and procedure codes available in administrative datasets. The seventeen different medical complications were assessed and the index scores were based on assigned weights for major and secondary diagnoses.

\section{Statistical Analysis}

Descriptive statistics were used to summarize the characteristics of the study subjects and to compare the differ- 
ences in gender, age, diagnosis, physical comorbidities (according to the $\mathrm{CCl}$ ), and hospital type between the two groups. Categorical variables were analyzed using the chi-squire test, and continuous variables were assessed using the Wilcoxon rank-sum test. The covariates in our study were factors that have been found to be associated with risk of hospitalization in previous studies. ${ }^{19-21)}$ Another reason for considering the type of hospital as a covariate was to avoid variations in medical cost in hospitals of different types (for example, a regional hospital might charge less than a medical center for an ED visit). The reason for using the non-parameter method was that the data in our study were not of a normal distribution. In addition, the possibility of multicollinearity was examined for group differences and other covariates $(\varphi=-0.18$ 0.45 , ps $<0.046$ ). Previous evidence has shown that a high level of multicollinearity might exist if the phi coefficient $(\varphi)$ is greater than $0.7 .{ }^{22)}$

The primary analysis of this study was to determine whether patient hospitalization within 24 hours of presentation at the ED was associated with the risk of readmission. To evaluate the risk of readmission in both groups, multiple logistic regression models were used to estimate the odds ratios (ORs) along with the 95\% confidence intervals (Cls) within 3, 7, 14 or 28 days. The ORs were adjusted by age, gender, type of hospital, delirium diagnosis and $\mathrm{CCl}$ score. The secondary analysis of this study was to stratify the data by $\mathrm{CCl}$ score, as well as by age, and to investigate the association of hospitalization within 24 hours with readmission risk in patients of different ages and with different CCl scores. In this study, the healthcare cost was taken as the direct cost obtained from $\mathrm{NHI}$ data. The healthcare cost of readmission was measured respectively for each group within 28 days after the index date. To evaluate cost-effectiveness in the two groups, the incremental cost-effectiveness ratio (ICER) was estimated in order to investigate whether the benefit to patients who received treatment following hospitalization was greater than that to patients who were not hospitalized within 24 hours. All significance levels were defined as two-sided, with $p<0.05$. We performed all statistical analyses using SAS (version 9.3 for Windows; SAS Institute Inc., Cary, NC, USA).

Table 1. Demographic characteristics of the patients with delirium $(n=2,780)$

\begin{tabular}{|c|c|c|c|}
\hline Characteristic & $\begin{array}{l}\text { No hospitalization within } \\
24 \text { hours }(n=1,485)\end{array}$ & $\begin{array}{l}\text { Hospitalization within } \\
24 \text { hours }(n=1,295)\end{array}$ & $p$ value \\
\hline Gender & & & 0.43 \\
\hline Female & $676(45.5)$ & $570(44.0)$ & \\
\hline Male & 809 (54.5) & 725 (56.0) & \\
\hline Age (yr) & $57.68 \pm 21.89$ & $65.77 \pm 19.15$ & $<0.0001$ \\
\hline$<65$ & 829 (55.8) & $491(37.9)$ & \\
\hline$\geq 65$ & $656(44.2)$ & $804(62.1)$ & \\
\hline Diagnosis & & & 0.0003 \\
\hline Substance-induced delirium & $108(7.3)$ & $56(4.3)$ & \\
\hline Senile delirium & $74(5.0)$ & $43(3.3)$ & \\
\hline Other conditions-related delirium & $1,303(87.7)$ & $1,196(92.4)$ & \\
\hline $\mathrm{CCl}$ & & & $<0.0001$ \\
\hline 0 & $541(36.4)$ & $195(15.1)$ & \\
\hline 1 & $275(18.5)$ & $223(17.2)$ & \\
\hline 2 & $206(13.9)$ & $202(15.6)$ & \\
\hline$\geq 3$ & $463(31.2)$ & $675(52.1)$ & \\
\hline $\mathrm{CCl}$ & $1.95 \pm 2.35$ & $3.32 \pm 2.90$ & $<0.0001$ \\
\hline Type of hospital & & & 0.04 \\
\hline Medical center & $345(23.2)$ & $316(24.4)$ & \\
\hline District hospital & $562(37.9)$ & $535(41.3)$ & \\
\hline Regional hospital & $578(38.9)$ & $444(34.3)$ & \\
\hline
\end{tabular}

Values are presented as number (\%) or mean \pm standard deviation.

$\mathrm{CCl}$, Charlson's comorbidity index.

Diagnosis was classified according to the International Classification of Diseases, Ninth Revision, Clinical Modification (ICD-9-CM). Substance-induced delirium: 291.0, 292.81; senile delirium: 290.11, 290.3, 290.41; other conditions-related delirium: 293.0, 293.1, 780.09. 


\section{RESULTS}

Table 1 shows the basic demographic data of the participants. The patients who were admitted to hospital within 24 hours of presentation at the ED were older than those who were not admitted immediately $(65.8 \pm 19.2 \mathrm{vs}$. $57.7 \pm 21.9, p<0.0001)$. The gender ratio was similar in both groups. The patients with delirium who were hospitalized immediately had higher $\mathrm{CCl}$ scores than the patients who were not hospitalized immediately $(3.32 \pm 2.90$ vs. $1.95 \pm 2.35, p<0.0001)$. Details of the $\mathrm{CCl}$ score analysis are presented in Table 2.

As shown in Table 3, comparing the readmission risk between the non-immediate hospitalization and the immediate hospitalization groups, the results showed a significantly higher OR of re-hospitalization within 7 days when all covariates were unadjusted (OR, $1.45[95 \% \mathrm{Cl}$, 1.12-1.89]; $p=0.0003)$. Furthermore, higher ORs of re-hospitalization also existed within 3 days (adjusted odds ratio [AOR], 1.90 [95\% Cl, 1.35-2.70]; $p=0.0003$ ), 14 days (AOR, 1.49 [95\% Cl, 1.17-1.89]; $p=0.001$ ), and even within 28 days of discharge from the ED (AOR, 1.42 [95\% Cl, 1.15-1.75]; $p=0.001)$ after adjustment for all covariates. In our second analysis, we further divided the subjects into different groups according to the level of severity of physical comorbidities $(\mathrm{CCl})$ and age. The results showed that when the $\mathrm{CCl}$ was lower than 3 (i.e., $\mathrm{CCl}$ from 0 to 2), no significant difference in the readmission risk existed between the groups. However, the non-immediately hospitalized patients with more severe complications $(\mathrm{CCl} \geq 3)$ had significantly higher ORs of re-hospitalization both in unadjusted and adjusted analyses from 3 days (AOR, 2.46 [95\% Cl, 1.53-3.97]; $p=0.0002$ ) to 28 days after discharge from the ED (AOR, $1.88[95 \% \mathrm{Cl}$, 1.42-2.50]; $p<0.0001)$ than the patients who were immediately hospitalized with more severe complications $(\mathrm{CCl} \geq 3)$. Also, in patients older than 65 years, both the unadjusted and the adjusted ORs of re-hospitalization for the non-immediate admission group were approximately 2.4-fold those of the immediate admission group at 3 days (AOR, 2.46 [95\% Cl, 1.58-3.85]; $p<0.0001$ ) and 1.8-fold those at 4 weeks after discharge (AOR, $1.82[95 \% \mathrm{Cl}$, 1.40-2.36]; $p<0.0001$ ).

As shown in Table 4, there were no significant differences in medical healthcare cost between the groups when the $\mathrm{CCl}<3$; however, when the $\mathrm{CCl} \geq 3$, patients
Table 2. Charlson's comorbidity index in patients with and without immediate hospitalization

\begin{tabular}{|c|c|c|c|}
\hline Variable & $\begin{array}{c}\text { No hospitalization } \\
\text { within } 24 \text { hours } \\
(n=1,485)\end{array}$ & $\begin{array}{c}\text { Hospitalization } \\
\text { within } 24 \text { hours } \\
\quad(n=1,295)\end{array}$ & $p$ value \\
\hline \multicolumn{3}{|c|}{ Myocardial infarction } & \multirow[t]{3}{*}{0.0003} \\
\hline No & $1,466(98.7)$ & $1,252(96.7)$ & \\
\hline Yes & $19(1.3)$ & $43(3.3)$ & \\
\hline \multicolumn{3}{|c|}{ Congestive heart failure } & \multirow[t]{3}{*}{$<0.0001$} \\
\hline No & $1,354(91.2)$ & $1,081(83.5)$ & \\
\hline Yes & $131(8.8)$ & $214(16.5)$ & \\
\hline \multicolumn{3}{|c|}{ Peripheral vascular disease } & \multirow[t]{3}{*}{0.26} \\
\hline No & $1,433(96.5)$ & $1,239(95.7)$ & \\
\hline Yes & $52(3.5)$ & $56(4.3)$ & \\
\hline \multicolumn{3}{|c|}{ Cerebrovascular disease } & \multirow[t]{3}{*}{$<0.0001$} \\
\hline No & $1,117(75.2)$ & $692(53.4)$ & \\
\hline Yes & $368(24.8)$ & $603(46.6)$ & \\
\hline \multicolumn{3}{|l|}{ Dementia } & \multirow[t]{3}{*}{0.70} \\
\hline No & $1,285(86.5)$ & $1,114(86.0)$ & \\
\hline Yes & $200(13.5)$ & $181(14.0)$ & \\
\hline \multicolumn{3}{|c|}{ Chronic pulmonary disease } & \multirow[t]{3}{*}{0.004} \\
\hline No & $1,222(82.3)$ & $1,009(77.9)$ & \\
\hline Yes & $263(17.7)$ & $286(22.1)$ & \\
\hline \multicolumn{3}{|c|}{ Rheumatologic disease } & \multirow[t]{3}{*}{0.12} \\
\hline No & $1,456(98.1)$ & $1,258(97.1)$ & \\
\hline Yes & $29(2.0)$ & $37(2.9)$ & \\
\hline \multicolumn{3}{|c|}{ Ulcer disease } & \multirow[t]{3}{*}{0.0001} \\
\hline No & $1,191(80.2)$ & $959(74.1)$ & \\
\hline Yes & $294(19.8)$ & $336(26.0)$ & \\
\hline \multicolumn{3}{|c|}{ Mild liver disease } & \multirow[t]{3}{*}{$<0.0001$} \\
\hline No & $1,386(93.4)$ & $1,149(88.7)$ & \\
\hline Yes & $99(6.7)$ & $146(11.3)$ & \\
\hline \multicolumn{3}{|c|}{ Diabetes (mild to moderate) } & \multirow[t]{3}{*}{$<0.0001$} \\
\hline No & $1,131(76.2)$ & $859(66.3)$ & \\
\hline Yes & $354(23.8)$ & $436(33.7)$ & \\
\hline \multicolumn{3}{|c|}{ Diabetes with chronic complications } & $<0.0001$ \\
\hline No & $1,287(86.7)$ & $1,052(81.2)$ & \\
\hline Yes & $198(13.33)$ & $243(18.8)$ & \\
\hline Hemiplegia & r paraplegia & & $<0.0001$ \\
\hline No & $1,443(97.2)$ & $1,207(93.2)$ & \\
\hline Yes & $42(2.8)$ & $88(6.8)$ & \\
\hline Renal disea & & & $<0.0001$ \\
\hline No & $1,387(93.4)$ & $1,119(86.4)$ & \\
\hline Yes & $98(6.6)$ & $176(13.6)$ & \\
\hline Any malign & cy, including leuken & ia and lymphoma & $<0.0001$ \\
\hline No & $1,389(93.5)$ & $1,122(86.6)$ & \\
\hline Yes & $96(6.5)$ & $173(13.4)$ & \\
\hline Moderate o & severe liver disease & & $<0.0001$ \\
\hline No & $1,450(97.6)$ & $1,215(93.8)$ & \\
\hline Yes & $35(2.4)$ & $80(6.2)$ & \\
\hline Metastatic s & lid tumor & & $<0.0001$ \\
\hline No & $1,465(98.7)$ & $1,235(95.4)$ & \\
\hline Yes & $20(1.4)$ & $60(4.6)$ & \\
\hline AIDS & & & - \\
\hline No & $1,485(100.0)$ & 1,295 (100.0) & \\
\hline Yes & $0(0.0)$ & $0(0.0)$ & \\
\hline
\end{tabular}

Values are presented as number (\%).

AIDS, acquired immune deficiency syndrome. 
Table 3. Odds ratios (ORs) of readmission risk for patients with delirium with or without hospitalization within 24 hours

\begin{tabular}{|c|c|c|c|c|}
\hline Variable & $\begin{array}{l}\text { No admission within } \\
24 \text { hours }(n=1,485)\end{array}$ & $\begin{array}{l}\text { Admission within } \\
24 \text { hours }(n=1,295)\end{array}$ & Unadjusted OR* & Adjusted $^{\dagger} \mathrm{OR}^{*}$ \\
\hline \multicolumn{5}{|c|}{ ORs for re-hospitalization within 3 days in patients with delirium } \\
\hline Overall & $99(6.7)$ & $59(4.6)$ & $1.49(1.08-2.08)$ & $1.89(1.35-2.70)$ \\
\hline \multicolumn{5}{|l|}{$\mathrm{CCl}$} \\
\hline 0 & $23(1.6)$ & $8(0.6)$ & $1.04(0.46-2.38)$ & $1.15(0.50-2.63)$ \\
\hline 1 & $15(1.0)$ & $6(0.5)$ & $2.08(0.79-5.56)$ & $2.50(0.92-6.67)$ \\
\hline 2 & $13(0.9)$ & $12(0.9)$ & $1.06(0.47-2.38)$ & $1.20(0.53-2.78)$ \\
\hline$\geq 3$ & $48(3.2)$ & $33(2.5)$ & $2.27(1.43-3.57)$ & $2.44(1.54-4.00)$ \\
\hline \multicolumn{5}{|l|}{ Age (yr) } \\
\hline$<65$ & $38(2.6)$ & $25(1.9)$ & $0.89(0.53-1.49)$ & $1.35(0.77-2.38)$ \\
\hline$\geq 65$ & $61(4.1)$ & $34(2.6)$ & $2.33(1.52-3.57)$ & $2.44(1.59-3.85)$ \\
\hline \multicolumn{5}{|c|}{ ORs for re-hospitalization within 7 days in patients with delirium } \\
\hline Overall & $163(11.0)$ & $101(7.8)$ & $1.45(1.12-1.89)$ & $1.89(1.43-2.50)$ \\
\hline \multicolumn{5}{|l|}{$\mathrm{CCl}$} \\
\hline 0 & $33(2.2)$ & $13(1.0)$ & $0.91(0.47-1.75)$ & $1.00(0.51-1.96)$ \\
\hline 1 & $27(1.8)$ & $11(0.8)$ & $2.08(1.02-4.35)$ & $2.33(1.12-5.00)$ \\
\hline 2 & $24(1.6)$ & $20(1.5)$ & $1.20(0.64-2.22)$ & $1.30(0.68-2.50)$ \\
\hline$\geq 3$ & $79(5.3)$ & $57(4.4)$ & $2.22(1.54-3.23)$ & $2.44(1.69-3.57)$ \\
\hline \multicolumn{5}{|l|}{ Age (yr) } \\
\hline$<65$ & $60(4.0)$ & $39(3.0)$ & $0.90(0.60-1.37)$ & $1.18(0.75-1.85)$ \\
\hline$\geq 65$ & $103(6.9)$ & $62(4.8)$ & $2.22(1.59-3.13)$ & $2.50(1.75-3.45)$ \\
\hline \multicolumn{5}{|c|}{ ORs for re-hospitalization within 14 days in patients with delirium } \\
\hline Overall & $197(13.3)$ & 154 (11.9) & $1.14(0.90-1.43)$ & $1.49(1.18-1.89)$ \\
\hline \multicolumn{5}{|l|}{$\mathrm{CCl}$} \\
\hline 0 & $39(2.6)$ & $17(1.3)$ & $0.81(0.45-1.47)$ & $0.90(0.49-1.67)$ \\
\hline 1 & $32(2.2)$ & $17(1.3)$ & $1.59(0.86-2.94)$ & $1.75(0.93-3.33)$ \\
\hline 2 & $26(1.8)$ & $25(1.9)$ & $1.02(0.57-1.85)$ & $1.12(0.61-2.04)$ \\
\hline$\geq 3$ & $100(6.7)$ & $95(7.3)$ & $1.67(1.23-2.27)$ & $1.82(1.32-2.50)$ \\
\hline \multicolumn{5}{|l|}{ Age (yr) } \\
\hline$<65$ & $71(4.8)$ & $57(4.4)$ & $0.71(0.49-1.03)$ & $0.99(0.67-1.47)$ \\
\hline$\geq 65$ & $126(8.5)$ & $97(7.5)$ & $1.72(1.30-2.33)$ & $1.92(1.43-2.56)$ \\
\hline \multicolumn{5}{|c|}{ ORs for re-hospitalization within 28 days in patients with delirium } \\
\hline Overall & $267(18.0)$ & $225(17.4)$ & $1.04(0.85-1.27)$ & $1.43(1.15-1.75)$ \\
\hline \multicolumn{5}{|l|}{$\mathrm{CCl}$} \\
\hline 0 & $51(3.4)$ & $24(1.9)$ & $0.74(0.44-1.23)$ & $0.81(0.48-1.37)$ \\
\hline 1 & $38(2.6)$ & $29(2.2)$ & $1.08(0.64-1.79)$ & $1.22(0.71-2.08)$ \\
\hline 2 & $38(2.6)$ & $35(2.7)$ & $1.08(0.65-1.79)$ & $1.19(0.70-2.00)$ \\
\hline$\geq 3$ & $140(9.4)$ & $137(10.6)$ & $1.69(1.30-2.22)$ & $1.89(1.41-2.50)$ \\
\hline \multicolumn{5}{|l|}{ Age (yr) } \\
\hline$<65$ & $96(6.5)$ & $81(6.3)$ & $0.66(0.48-0.91)$ & $0.94(0.67-1.33)$ \\
\hline$\geq 65$ & $171(11.5)$ & $144(11.1)$ & $1.61(1.25-2.08)$ & $1.82(1.41-2.38)$ \\
\hline
\end{tabular}

Values are presented as number (\%) or OR (95\% confidence interval).

$\mathrm{CCl}$, Charlson's comorbidity index.

*ORs were in comparison with hospitalization within 24 hours.

${ }^{\dagger}$ ORs were adjusted for age ( $<65$ or $\geq 65$ years), gender, type of hospital, $\mathrm{CCl}(0,1,2$, or $\geq 3)$ and diagnosis.

without immediate admission incurred a significantly greater medical cost during the re-hospitalization period within 28 days ( $p=0.002)$. Elderly subjects without immediate admission also incurred a significantly greater healthcare cost after readmission within 28 days $(p=$ 0.0008). However, when the patient was under 65 years of age, the cost of readmission within 28 days was lower for patients who were not admitted immediately in comparison with patients who were hospitalized within 24 hours ( $p=0.004$ ).

To investigate cost-effectiveness in the two groups, ICERs were estimated as the cost difference (healthcare cost in patients hospitalized within 24 hours minus healthcare cost in patients not hospitalized within 24 
hours) divided by the effect difference (re-hospitalization rate in patients hospitalized within 24 hours minus re-hospitalization rate in patients not hospitalized within 24 hours). Table 5 shows the ICERs in the two groups under different $\mathrm{CCl}$ scores. Based on the analysis, patients who were hospitalized for treatment had a lower re-hospitalization rate and a lower medical cost than patients who were not hospitalized (cost difference $=-753$, effect difference $=-0.61$, ICER=1,234.4). The greater the patient comorbidity severity, the greater the decrease in the re-hospitalization rate and the medical cost in patients who were hospitalized for treatment within 24 hours of presentation at the $\mathrm{ED}(\mathrm{CCl} \geq 3$ cost difference $=-14,353$,

Table 4. Healthcare cost of re-hospitalization after first onset of delirium at the emergency department

\begin{tabular}{cccc}
\hline Variable & $\begin{array}{c}\text { No hospitalization } \\
\text { within 24 hours } \\
(\mathrm{n}=1,485)\end{array}$ & $\begin{array}{c}\text { Hospitalization } \\
\text { within 24 hours } \\
(\mathrm{n}=1,295)\end{array}$ & $p$ value \\
\hline $\mathrm{CCl}$ & & & \\
0 & $6,454 \pm 32,014$ & $16,643 \pm 81,408$ & 0.23 \\
1 & $12,179 \pm 52,857$ & $8,485 \pm 32,396$ & 0.69 \\
2 & $19,046 \pm 79,932$ & $13,938 \pm 44,174$ & 0.74 \\
$\geq 3$ & $38,521 \pm 225,616$ & $24,168 \pm 81,810$ & 0.002 \\
Age (yr) & & & \\
$<65$ & $9,492 \pm 44,175$ & $18,103 \pm 71,048$ & 0.004 \\
$\geq 65$ & $31,601 \pm 193,896$ & $19,126 \pm 70,552$ & 0.0008 \\
\hline
\end{tabular}

Values are presented as mean \pm standard deviation.

$\mathrm{CCl}$, Charlson's comorbidity index.

Healthcare cost (New Taiwan dollar, NT\$) was the direct cost obtained from National Health Insurance data the exchange rate was 1.00 US dollar=31.517 NT\$ in 2008. effect difference $=-9.94, \mathrm{ICER}=444.0)$.

\section{DISCUSSION}

Previous studies have demonstrated the subsequent re-hospitalization risk and the cost of treating delirium patients after admission. ${ }^{15,19)}$ Our study further indicated that patients who were not immediately admitted from the ED had a greater risk of readmission within 28 days, in particular subjects with severe clinical comorbidities and those of a greater age. Also, patients who were not immediately hospitalized during their first visit to the ED incurred a greater subsequent healthcare cost during readmission.

Our results highlighted the fact that the higher readmission risk lasted for 28 days in delirium patients who were not immediately admitted from the ED. This result is consistent with the benefits of hospitalization identified in previous studies. ${ }^{8)}$ Whilst delirium symptoms may be detected prior to the deterioration of physical conditions, ${ }^{5,23)}$ several diseases may be exacerbated progressively rather than causing rapid deterioration; for example, the high percentages of congestive heart failure, chronic obstructive pulmonary disease, ulcer disease, and stroke, as listed in Table 2. These diseases might result in a persistently greater risk of readmission. Another important finding was that even though a statistically higher readmission risk was identified in the non-immediate admission group, the actual numbers and percentages related to readmission were similar (18\%) in both groups after the 28-day follow-up period in this study. As the mean age in

Table 5. The incremental cost-effectiveness ratio between patients with or without hospitalization within 24 hours

\begin{tabular}{|c|c|c|c|c|c|c|c|}
\hline \multirow{2}{*}{$\begin{array}{l}\text { Hospitalization } \\
\text { in days }\end{array}$} & \multicolumn{2}{|c|}{$\begin{array}{l}\text { No hospitalization within } \\
24 \text { hours }(n=1,485)\end{array}$} & \multicolumn{2}{|c|}{$\begin{array}{l}\text { Hospitalization within } \\
24 \text { hours }(n=1,295)\end{array}$} & \multirow{2}{*}{$\begin{array}{c}\text { Cost difference } \\
\qquad \mathrm{C} 1-\mathrm{CO}\end{array}$} & \multirow{2}{*}{$\begin{array}{c}\text { Effect difference } \\
\text { E1-E0 }\end{array}$} & \multirow{2}{*}{ ICER } \\
\hline & $\begin{array}{l}\text { Mean healthcare } \\
\text { cost }(\mathrm{C} 0)\end{array}$ & $\begin{array}{l}\text { Re-hospitalization } \\
\text { rate (E0) }\end{array}$ & $\begin{array}{c}\text { Mean healthcare } \\
\text { cost }(\mathrm{C} 1)\end{array}$ & $\begin{array}{l}\text { Re-hospitalization } \\
\text { rate (E1) }\end{array}$ & & & \\
\hline $\begin{array}{l}\text { Overall } \\
\mathrm{CCl}\end{array}$ & 25,254 & 17.98 & 24,501 & 17.37 & -753 & -0.61 & $1,234.4$ \\
\hline 0 & 6,454 & 9.43 & 16,643 & 12.31 & 10,189 & 2.88 & $3,537.8$ \\
\hline 1 & 12,179 & 13.82 & 8,485 & 13.00 & $-3,694$ & -0.82 & $4,504.9$ \\
\hline 2 & 19,046 & 18.45 & 13,938 & 17.33 & $-5,108$ & -1.12 & $4,560.7$ \\
\hline$\geq 3$ & 38,521 & 30.24 & 24,168 & 20.30 & $-14,353$ & -9.94 & $1,444.0$ \\
\hline \multicolumn{8}{|l|}{ Age (yr) } \\
\hline$<65$ & 9,492 & 11.58 & 18,103 & 16.5 & 8,611 & 4.92 & $1,750.2$ \\
\hline$\geq 65$ & 31,601 & 26.07 & 19,126 & 17.91 & $-12,475$ & -8.16 & 1,528.8 \\
\hline
\end{tabular}

$\mathrm{CCl}$, Charlson's comorbidity index; ICER, incremental cost-effectiveness ratio; ICER=(C1-C0)/(E1-E0).

Healthcare cost (New Taiwan dollar, NT\$) was the direct cost obtained from National Health Insurance data; the exchange rate was 1.00 US dollar=31.517 NT\$ in 2008. 
the immediate admission group was significantly greater, the results might reflect the fact that clinicians deliver a higher level of care for the elderly in the ED, and the elderly are more vulnerable to readmission when delirium occurs. This serves as a reminder that younger patients with delirium should be carefully diagnosed and treated for a better prognosis.

A literature review demonstrated that approximately one-third of delirium patients with severe physical illnesses are discharged from the ED without hospitalization, and those with greater severities of physical illnesses have higher risks of readmission. ${ }^{3)}$ On the other hand, a greater age is another independent risk factor that enhances the risk of re-hospitalization after discharge from the ED. ${ }^{719)}$ Our results were in line with previous studies, and another issue that extended from the results of this study is worthy of discussion: the fact that the younger patients had the same non-significant risk in both groups, and the medical cost was lower in the non-immediate admission group when the patients were re-hospitalized. Therefore, close follow-up of patients with less severe physical comorbidities and those of a younger age may be optimal in addition to hospitalization management, as admission may increase the healthcare burden and even possibly the risk of infection. ${ }^{24)}$ The non-significant results for the younger patients and those with a lower $\mathrm{CCl}$ may also indicate that a shorter period of ED care might be appropriate for symptom observation when patients may not require inpatient care.

As noted previously, diagnosis of delirium in the ED may increase the burden of healthcare cost as compared with patients without delirium. ${ }^{19)}$ Our study showed that patients who were not immediately admitted from the ED who had more severe comorbidities or were of a greater age incurred a healthcare cost for re-hospitalization of almost two-fold the cost for patients who were admitted immediately. Patients with more severe physical conditions or vulnerable elderly patients may deteriorate once they have been discharged from the ED and are not receiving intensive care, and therefore the medical cost may increase when they are re-hospitalized. ${ }^{15)}$ The greater healthcare cost incurred in the non-immediate admission group was also in concordance with the above results, indicating that immediate hospitalization may be beneficial in terms of both lowering the readmission risk and reducing the healthcare cost, especially in patients with more severe comorbidities or older patients. Similar results were obtained in our cost-effectiveness analysis, showing that immediate admission may decrease both the healthcare cost and the risk of readmission in the severe $\mathrm{CCl}$ group and in older patients.

Several limitations existed in our study. First, several factors that may have influenced the results could not be controlled, including family support systems, medical health resources usage, medication adherence, etc. However, previous study showed that comorbidities and the severity of delirium might influence patient outcome more strongly than sociodemographic variables. ${ }^{25)}$ Also, the actual correlations between variables should be considered, even though low collinearity existed between all the variables in our study. Second, the follow-up period was only 28 days, and there was therefore a lack of longitudinal follow-up and mortality rate exploration. Third, delirium is underdiagnosed and undercoded in clinical practice, ${ }^{26)}$ which raise concerns regarding the accuracy of our claim-based disease definition. This could result in a conservative bias towards the null hypothesis. Also, the $\mathrm{CCl}$ score might not be able to be generalized to include all etiologies of delirium, which might lead to underestimation of the results. Furthermore, many clinicians neglect the diagnosis of delirium even if they have detected it because they may focus on the primary physical illness and regard delirium as a less-important secondary manifestation; this can be a source of selection bias, because coded delirium might be more serious, more frequently of a hyperactive form, or have an ambiguous direct cause as compared with un-coded delirium. Fourth, despite adjustment of confounders using statistical methods, we cannot completely rule out confounders in this observational (non-randomized) study. Fifth, the reasons for discharge from the ED could not be clarified in our study. Besides clinical decisions for discharge, some patients might decide to discharge themselves against medical advice for different reasons, ${ }^{27)}$ which may also lead to a higher readmission risk in the non-admission group. Finally, our data did not include costs in terms of loss of life, functional disability (such as persistent cognitive impairment), and other indirect costs (for example, costs of lost productivity or costs associated with litigation for related malpractice claims), which are also important in the cost analysis of delirium management.

In summary, our study highlighted that clinicians 
should carefully consider whether admission of patients with delirium is required before discharge, especially in patients with more severe comorbidities or older patients. In addition, more integrated and multi-interventional programs should be developed for patients with delirium upon discharge from hospital.

\section{Acknowledgments}

This research received funding from National Cheng Kung University Hospital (NCKUH-10403020 and NCKUH-10503011) and the Taiwanese Society of Psychiatry (TSOP-2012-R1). The funders had no role in the study design, data collection and analysis, decision to publish, or preparation of the manuscript. The authors declare that they have no conflicts of interest. The authors would like to thank National Cheng Kung University Hospital for their support and Mr. Chien Ting Lin for his administrative support.

\section{REFERENCES}

1. Elie M, Cole MG, Primeau FJ, Bellavance F. Delirium risk factors in elderly hospitalized patients. J Gen Intern Med 1998; 13:204-212.

2. Kakuma R, du Fort GG, Arsenault L, Perrault A, Platt RW, Monette J, et al. Delirium in older emergency department patients discharged home: effect on survival. I Am Geriatr Soc 2003;51:443-450.

3. Elie M, Rousseau F, Cole M, Primeau F, McCusker J, Bellavance F. Prevalence and detection of delirium in elderly emergency department patients. CMAJ 2000;163:977-981.

4. Press Y, Margulin T, Grinshpun Y, Kagan E, Snir Y, Berzak A, et al. The diagnosis of delirium among elderly patients presenting to the emergency department of an acute hospital. Arch Gerontol Geriatr 2009;48:201-204.

5. Gower LE, Gatewood MO, Kang CS. Emergency department management of delirium in the elderly. West J Emerg Med 2012;13:194-201.

6. Naughton BJ, Moran MB, Kadah H, Heman-Ackah $\mathrm{Y}$, Longano J. Delirium and other cognitive impairment in older adults in an emergency department. Ann Emerg Med 1995; 25:751-755.

7. Aminzadeh F, Dalziel WB. Older adults in the emergency department: a systematic review of patterns of use, adverse outcomes, and effectiveness of interventions. Ann Emerg Med 2002;39:238-247.

8. Lundström M, Edlund A, Karlsson S, Brännström B, Bucht G, Gustafson Y. A multifactorial intervention program reduces the duration of delirium, length of hospitalization, and mortality in delirious patients. J Am Geriatr Soc 2005;53:622-628.

9. Inouye SK, Viscoli CM, Horwitz RI, Hurst LD, Tinetti ME. $A$ predictive model for delirium in hospitalized elderly medical patients based on admission characteristics. Ann Intern Med 1993; 119:474-481.

10. Charlson ME, Pompei P, Ales KL, MacKenzie CR. A new method of classifying prognostic comorbidity in longitudinal studies: development and validation. J Chronic Dis 1987;40: 373-383.

11. Kieszak SM, Flanders WD, Kosinski AS, Shipp CC, Karp H. A comparison of the Charlson comorbidity index derived from medical record data and administrative billing data. J Clin Epidemiol 1999;52:137-142.

12. McCusker J, Cole MG, Dendukuri N, Belzile E. Does delirium increase hospital stay? J Am Geriatr Soc 2003;51:1539-1546.

13. Korc-Grodzicki B, Sun SW, Zhou Q, lasonos A, Lu B, Root JC, et al. Geriatric assessment as a predictor of delirium and other outcomes in elderly patients with cancer. Ann Surg 2015;261: 1085-1090.

14. Wang HY, Chew G, Kung CT, Chung KJ, Lee WH. The use of Charlson comorbidity index for patients revisiting the emergency department within 72 hours. Chang Gung Med J 2007; 30:437-444.

15. Leslie DL, Marcantonio ER, Zhang Y, Leo-Summers L, Inouye SK. One-year health care costs associated with delirium in the elderly population. Arch Intern Med 2008;168:27-32.

16. Wu TY, Majeed A, Kuo KN. An overview of the healthcare system in Taiwan. London J Prim Care (Abingdon) 2010;3: 115-119.

17. Singer AJ, Thode HC Jr, Viccellio P, Pines JM. The association between length of emergency department boarding and mortality. Acad Emerg Med 2011;18:1324-1329.

18. Deyo RA, Cherkin DC, Ciol MA. Adapting a clinical comorbidity index for use with ICD-9-CM administrative databases. J Clin Epidemiol 1992;45:613-619.

19. Kennedy M, Enander RA, Tadiri SP, Wolfe RE, Shapiro NI, Marcantonio ER. Delirium risk prediction, healthcare use and mortality of elderly adults in the emergency department. J Am Geriatr Soc 2014;62:462-469.

20. Lipowski ZJ. Delirium (acute confusional states). JAMA 1987;258:1789-1792.

21. Ahmed S, Leurent B, Sampson EL. Risk factors for incident delirium among older people in acute hospital medical units: a systematic review and meta-analysis. Age Ageing 2014;43: 326-333.

22. Tabachnick BG, Fidell LS. Using multivariate statistics. 5th ed. Boston:Pearson/Al/yn and Bacon;2007.

23. Saczynski JS, Inouye SK. Delirium. In: Steffens DC, Blazer DG, Thakur ME, editors. The American Psychiatric Publishing textbook of geriatric psychiatry. 5th ed. Washington, DC.: American Psychiatric Publishing;2015. p.155-176.

24. Johnston SL, Pattemore PK, Sanderson G, Smith S, Campbell MJ, Josephs LK, et al. The relationship between upper respiratory infections and hospital admissions for asthma: a timetrend analysis. Am J Respir Crit Care Med 1996;154:654-660. 
25. Bellelli G, Magnifico F, Trabucchi M. Outcomes at 12 months in a population of elderly patients discharged from a rehabilitation unit. J Am Med Dir Assoc 2008;9:55-64.

26. Han JH, Eden S, Shintani A, Morandi A, Schnelle J, Dittus RS, et al. Delirium in older emergency department patients is an independent predictor of hospital length of stay. Acad Emerg Med 2011;18:451-457.

27. Saitz R, Ghali WA, Moskowitz MA. Characteristics of patients with pneumonia who are discharged from hospitals against medical advice. Am J Med 1999;107:507-509. 